\title{
4 CONCEPTOS DE SALUD E HISTORIA DE LA SANIDAD EN ESPAÑA
}

La salud es un estado del individuo y, en su dimensión social, del conjunto de la población. La Organización Mundial de la Salud —OMS—, en su XXX Asamblea, celebrada en 1977 en Alma — Ata, en la que se adoptó la estrategia de «Salud para todos en el año 2000», define la salud como: «un estado de bienestar físico, mental y social, y no consiste sólo en la ausencia de enfermedad» ${ }^{1}$. La definición de la salud adoptada por la OMS contiene varios conceptos que convienen subrayar:

-La salud no se define negativamente como la «ausencia de enfermedad», sino positivamente como estado de bienestar. Estar sano no es sólo no estar enfermo, sino poder desarrollar dentro de la sociedad todas las potencialidades del individuo.

- La salud no se corresponde solamente con los aspectos biológicos y psicológicos de los individuos, sino también con los de carácter social. Una política de salud como la definida por la OMS, conceptualizada desde la perspectiva holístico—humanista, se corresponde con el conjunto de la política social, y aun la trasciende si se toman en cuenta el conjunto de determinantes de la salud.

- No puede establecerse un patrón objetivo de salud, pues el estar sano está determinado social y psicológicamente, es decir, por patrones culturales e individualmente subjetivos, y no sólo por parámetros biológicos objetivos.

Esta dificultad es superada en los objetivos de salud propugnados por la OMS mediante una estrategia incrementalista:

1 XXX Asamblea de la Organización Mundial de al Salud [1978], en Elola [1994, pp. 39 y ss]. 
1. Añadir más años a la vida — reducir la mortalidad prematura y, por consiguiente, aumentar la esperanza de vida-.

2. Añadir más salud a la vida — reducir enfermedades, accidentes, minusvalías y discapacidades-.

3. Añadir más vida a los años, en el sentido de desarrollar las capacidades del individuo en el entorno privado, social y, dentro de este último, laboral.

La OMS no tiene problemas para desarrollar el conjunto de indicadores que permiten evaluar los progresos en el logro de los objetivos de añadir más años y más salud a la vida, pero se encuentra con un notable conjunto de dificultades para medir la «vida» añadida a los años. Los «Indicadores de Salud» — Secretaria General de Salud-, proporcionan una completa y rigurosa información sobre la evolución de estos indicadores en España.

TABLA 4.1. Principales indicadores de salud.

\begin{tabular}{|l|c|c|}
\hline Indica dor & Media de la UE & Espa ña \\
\hline Esperanza de vida al nacer, varones [1990-95] & 73,4 & 75 \\
\hline Esperanza de vida al nacer, mujeres [1990-95] & 79,8 & 80,5 \\
\hline Esperanza de vida con 65 años, varones [años, 1993] & na. & 13,8 \\
\hline Esperanza de vida con 65 años, mujeres [años, 1993] & na. & 16,8 \\
\hline Mortalidad infantil [por cada mil nacidos vivos, 1992] & 8.1 & 7.8 \\
\hline
\end{tabular}

(C) NERA [1997, p. 172] y Arthur Andersen [1996, p. 206].

TABLA 4.2. Gasto sanitario.

\begin{tabular}{|l|c|c|c|c|c|c|}
\hline \multirow{2}{*}{} & \multicolumn{2}{|c|}{$\begin{array}{l}\text { Gasto sanitario total } \\
\text { sobre el PIB (\%) }\end{array}$} & \multicolumn{2}{c|}{$\begin{array}{l}\text { Gasto sanitario público } \\
\text { sobre el gasto total (\%) }\end{array}$} & \multicolumn{2}{c|}{$\begin{array}{l}\text { Gasto sanitario público } \\
\text { sobre el PIB (\%) }\end{array}$} \\
\cline { 2 - 7 } & $\mathbf{1 9 7 0}$ & $\mathbf{1 9 9 5}$ & $\mathbf{1 9 7 0}$ & $\mathbf{1 9 9 5}$ & $\mathbf{1 9 7 0}$ & $\mathbf{1 9 9 5}$ \\
\hline Reino Unido & 4,5 & 6,9 & 87,0 & 84,1 & 3,9 & 5,8 \\
\hline España & 3,7 & 7,6 & 65,4 & 78,2 & 2,4 & 5,9 \\
\hline Alemania & 5,9 & 9,6 & 69,6 & 73,5 & 4,1 & 7,1 \\
\hline Francia & 5,8 & 9,9 & 74,7 & 78,4 & 4,3 & 7,8 \\
\hline Países Bajos & 5,9 & 8,8 & 84,3 & 77,5 & 5,0 & 6,8 \\
\hline
\end{tabular}

(C) Arthur Andersen [1996, p. 206]. 
El concepto de salud propugnado por la OMS puede complementarse con el de Lalonde ${ }^{2}$, quien definió el «campo de la salud», compuesto por cuatro elementos o factores que influyen sobre la salud:

1. Biología humana, que incluye aquellos aspectos relacionados con la salud, desarrollados en el cuerpo humano como consecuencia de su biología fundamental y de la constitución orgánica del individuo.

2. Medio ambiente, que incluye aquellos factores que se hallan fuera del cuerpo humano y sobre los cuales el individuo tiene poco o ningún control.

3. Estilo de vida, como suma de las decisiones individuales que afectan a la salud.

4. La sanidad, como organización de la atención a la salud, consiste en la calidad, cantidad, orden, índole y relaciones de personas y recursos en la prestación de atención a la salud.

El concepto de salud de Lalonde sitúa a la sanidad como un factor más, el cual junto con los tres restantes contribuye a la producción de salud. A pesar de los importantes recursos que se destinan a la sanidad en los países occidentales desarrollados, son los restantes factores — biología, medio ambiente y estilos de vida- quienes determinan en mayor medida la salud individual y colectiva.

Las dos concepciones de salud prevalentes, la de la OMS y, más evidentemente, la de «campo de salud», rompen la equivalencia entre salud y sanidad, situando a esta última como un factor más en la producción de salud. La salud no es, por tanto, un objetivo sectorial, exclusivo de la sanidad, sino de cada individuo y del conjunto de la sociedad: sistema educativo, sistema de relaciones laborales, sistema de protección social, redistribución de la riqueza, acceso a la vivienda, protección del entorno, etc.

La medicina — ciencia - y la sanidad —organización- constituyen, por tanto, factores que contribuyen al logro de la salud. La posición relativa que ocupa la sanidad en la producción de salud no le resta importancia. Una mala organización de los cuidados puede hacer que se utilicen los conocimientos médicos de forma socialmente ineficaz. Los Estados Unidos de América constituyen el paradigma de esta situación: estando situada la medicina de esta

2 Para Lalonde [1975] «la sanidad se asocia con la organización institucionalizada de los cuidados, y no atiende a la dimensión de cuidados no remunerados, prestados en el seno de la familia y generalmente por mujeres y que en España tiene enorme importancia», en Elola [1994, pp. 40-41]. 
nación a la cabeza científica y técnica de los países más desarrollados, su sanidad permite que, con el mayor gasto sanitario de entre los países de la OCDE más del $10 \%$ de su población carezca de cobertura sanitaria, y que sus indicadores sanitarios estén por debajo de la mayoría de los países desarrollados [Scheiber et al., 1992, pp. 1-15].

Esta situación hizo que la reforma del sistema sanitario de los Estados Unidos fuera una de las propuestas más relevantes del programa demócrata para las elecciones presidenciales de 1992; siendo, en la actualidad, una reforma a la que la nueva administración americana ha otorgado extraordinaria relevancia política —The President's Health Security Plan, 1993—.

\subsection{CONTRIBUCIÓN DE LA SANIDAD A LA PRODUCCIÓN DE SALUD}

Si la sanidad y, dentro de su organización, la aplicación de los conocimientos médicos, son sólo factores, entre otros, que contribuyen a la producción de la salud ¿se puede estimar su importancia relativa? Los datos disponibles son los siguientes:

1. Existe una manifiesta desproporción entre la relativa contribución de los distintos factores que influyen sobre la salud y los gastos directos que se destinan a cada uno de ellos. Mientras que se estima en un 11\% la contribución de la sanidad a reducir la mortalidad, al sistema sanitario se destinan el 90\% de los gastos directos en salud [Dever, 1976, p. 465].

2. Numerosos estudios internacionales comparados demuestran que, siendo la renta per cápita el indicador que mejor se correlaciona con los indicadores de salud de los distintos países, no existe evidencia de que mayores recursos sanitarios —gasto, médicos, camas hospitalarias - se traduzcan en mejores niveles de salud [McKinlay et al., 1989, pp. 181-208]. No se han encontrado relaciones significativas entre recursos sanitarios por áreas y las tasas de mortalidad evitable por intervención sanitaria [Knust et al., 1988, pp. 233-245; McKenbach, 1991, pp. 245-256]. Existen, incluso, paradojas como la correlación negativa entre número de médicos y peores indicadores de salud [Cochrane et al., 1978, pp. 200-205]. El

3. Para mayor información sobre «The President's Health Security Plan, 1993», consultar Ivey [1994], Vallbona [1994], Saltman [1994], Navarro [1993] y López y Puig [1993], entre otros. 
que un mayor número de médicos pueda relacionar con peores indicadores sanitarios, probablemente lo que refleja es una mala organización de la sanidad. En este sentido, se debe recordar que España, aunque tiene la mayor tasa de médicos por habitante de los países occidentales desarrollados, disfruta de indicadores de salud similares a los de la media de la Comunidad Europea.

3. Aunque la cobertura sanitaria parece reducir el riesgo de mortalidad [Franks et al., 1993, pp. 737_ 741], el aseguramiento universal, por si mismo, no reduce significativamente las diferencias de salud vinculadas al status socioeconómico [Adler et al., 1993, pp. 3140_3145]. Este aumento de la desigualdad era debido a que la mejoría en los niveles de salud, que experimentaban todos los estratos socioeconómicos, había sido mayor para los niveles más altos. Este hecho se debe, probablemente, a que el acceso a los servicios sanitarios no corrige desigualdades en salud producidas por factores socioeconómicos —educación, renta-, los cuales actúan como importantes factores determinantes [Angell, 1993, pp. 126-127; Feinstein, 1993, pp. 279_322], en especial durante la infancia [Kaplan y Salonen, 1992, pp. 16-21].

4. La productividad marginal, o relación entre los aumentos del gasto sanitario y la mejora en indicadores de salud, de los sistemas sanitarios en los países occidentales desarrollados parece disminuir a partir de un determinado nivel de gasto [McGuire et al., 1992, en Elola, 1994, p. 44], que resulta específico para cada país.

5. Para algunos de los procedimientos más frecuentemente utilizados en medicina, la evidencia existente sobre su eficacia es de tan mala calidad, que es virtualmente imposible determinar sus efectos sobre los pacientes [Eddy et al., 1988, pp. 19-32]. Se estimó que, del conjunto de técnicas empleadas sobre pacientes, solamente del 10 al $20 \%$ estaban sustentadas sobre evidencia científica como más útiles y beneficiosas que inútiles e, incluso, peligrosas. Esta estimación es muy similar a la que Eddy suministra para los procedimientos, principalmente quirúrgicos, que evalúa, en la que sólo un 15\% estaban respaldados por trabajos realizados con suficiente rigor. El creciente interés por asegurar la eficacia y seguridad de equipos productos, así como por la evaluación social de las tecnologías sanitarias, es posible que contribuya, en un futuro inmediato, a mejorar este dato. 
6. La ausencia de consenso sobre la eficacia clínica o las indicaciones precisas de muchos procedimientos, como las cesáreas, las operaciones de amígdalas o de varices, hace que se produzcan importantes variaciones - no justificadas por diferencias epidemiológicas - en su práctica, cuando se compara la tasa — número de intervenciones dividido por la población - de estas intervenciones entre países o entre áreas geográficas dentro del mismo país [Wennberg, 1987, pp. 2568-2569; Sarría y Sendra, 1993, pp. 63-69].

7. Algunos autores [Fuchs, 1984, pp. 1572-1573] estiman que hasta un $20 \%$ del gasto sanitario se destina a procedimientos perjudiciales o ineficaces, y que un $20-25 \%$ de los procedimientos realizados en Estados Unidos, están basados en indicaciones inapropiadas o dudosas, por lo que, eliminando procedimientos ineficaces e indicaciones inapropiadas, se podría reducir sustancialmente el gasto sanitario y, a su vez, mejorar la salud.

Los datos referidos no niegan la importante contribución de la medicina a la mejora de la salud y calidad de vida. Sin embargo, la sanidad, como organización de los cuidados, puede incentivar la eficiente utilización social de la medicina o, por el contrario, estimular su uso irracional.

En este sentido, la sanidad determinaría, condicionando el uso racional de la tecnología médica, lo que se puede llamar la «curva de eficiencia» [Elola, 1994, p. 45], del sistema sanitario de cada nación, o relación entre recursos empleados y su traducción en la mejora de la salud de la población.

Esta interpretación de los datos mencionados más arriba — los cuales pueden parecer, en un principio, contradictorios- explica dos hechos:

- En las comparaciones entre países distintos puede no haber relación entre gasto sanitario e indicadores de salud, al ser diferente la eficiencia de los distintos sistemas — un país con buena sanidad puede alcanzar mejores resultados en salud con menor gasto que otro con peor organización-; mientras que esta relación entre gasto sanitario y salud puede encontrarse, con un rendimiento decreciente, para un determinado sistema —aunque la eficiencia de un sistema sea escasa, cuantos mayores recursos utilice, existirán mayores posibilidades de producir mejoras en salud-. Esta explicación se contradice, en parte, por los hallazgos empíricos que demuestran una escasa correlación, para cada país, entre variabilidad en las tasas de mortalidad por causa sanitariamente evitable y la disponibilidad de recursos en las áreas 
[Knust et al., 1988, pp. 233-245; McKinlay et al., 1989, pp. 181208]. Sin embargo, las bajas tasas de mortalidad por estas causas, problemas de clasificación, la propia organización del sistema sanitario - por ejemplo, disponer de un adecuado sistema de referencia y evacuación hacia otras áreas con mayores recursos- y lo excesivamente grosero del indicador utilizado —mortalidad-, ponen en duda la adecuación de este tipo de estudios para establecer algún tipo de relación entre recursos sanitarios y mejoras en los niveles de salud, [Elola, 1994, p. 47].

- La sanidad es expresión del contexto económico y social en el que se desenvuelve, este marco social, a su vez, limita su eficacia. Esto explicaría que los sistemas de cobertura universal tenga una limitada eficacia en la corrección, en términos relativos, de las desigualdades en salud entre distintos estratos socioeconómicos de la población.

La sanidad condiciona la utilización de la ciencia y tecnología médica en la aplicación de las técnicas y procedimientos, así como en la utilización de equipos y productos sanitarios, lo que tiene importantes repercusiones económicas. Por ello, existen intereses encontrados de los distintos agentes en relación con el modelo organizativo de la asistencia sanitaria.

La información disponible impide establecer una correlación biunívoca entre sanidad y salud, o sustentar la afirmación de que cuanta más sanidad — mayor gasto sanitario, por ejemplo— más salud, o legitimar cualquier actuación médica en el estado del arte. Todos los problemas de la sanidad son susceptibles de perfeccionamiento mediante el debate público, en especial la relación entre el producto de los servicios sanitarios y la producción de salud, así como la capacidad de una determinada organización de los cuidados para incentivar, o no, la más eficiente utilización social de los cuidados médicos.

Antes de adentrarse en la relación entre sistemas sanitarios y salud de la población conviene llamar la atención sobre un punto que puede pasar desapercibido desde una aproximación tecnocrática a esta relación. Los servicios sanitarios son expresión de los valores de una sociedad; en general, se puede esperar que los Servicios Nacionales de Salud, basados en una ideología más igualitaria que individualista, sean una pieza más de sistemas de protección social de carácter universal, impulsados por políticas socialdemócratas. En este contexto, es muy probable que mejores indicadores de salud de la población estén reflejando no sólo un buen funcionamiento de la sanidad, sino que también son resultado de una sociedad más equitativa, con menores 
desigualdades en la distribución de la renta y mayores oportunidades de acceso a una educación de calidad, con independencia del nivel socioeconómico [Elola, 1994, p. 48].

\subsection{LA DEMANDA SANITARIA}

Se sabe que en la actualidad todos los sistemas sanitarios del mundo occidental se enfrentan a dos grandes retos:

- El aumento continuo de la demanda de asistencia sanitaria, cada vez más amplia y de mayor calidad.

- La necesidad de contener el gasto público destinado a la sanidad, teniendo en cuenta la realidad económica de cada país.

El incremento de la demanda se deriva de los cambios demográficos, de la aparición de nuevas enfermedades, de las modificaciones de la estructura familiar y cultural, así como de la gran tecnificación a la que se ha visto sometida la sanidad.

La situación demográfica de España, al igual que en los países del entorno, se caracteriza por el rápido proceso de envejecimiento experimentado en los últimos 30 años. En España, las proyecciones de población estiman que, en el año 2000, el 15\% de la población española tendrá más, de 65 años, tendiendo a aumentar esta proporción en años posteriores.

Las personas mayores, junto con las necesidades de atención específicamente sanitarias, requieren cada vez más cuidados de tipo social, sin que la frontera entre lo sanitario y lo social esté claramente definida en todos los casos. Este hecho, conlleva la posibilidad de que se produzcan solapamientos no deseados entre ambos tipos de atención.

Por otra parte, se están produciendo cambios en el patrón de morbimortalidad. Las patologías infecciosas del siglo pasado y de la primera mitad de éste, fundamentalmente de carácter infecto-contagioso, han sido sustituidas por enfermedades de carácter crónico y degenerativo - cardiovasculares y cáncer-, que son enormemente costosas, invalidantes y de difícil tratamiento.

Además, hay que añadir la aparición de nuevas patologías como el SIDA, cuyo carácter letal e impacto social supone no sólo un gran coste, sino nuevos problemas de asistencia y de marginación social.

Los cambios en el seno de la familia, cada vez menos inclinada a proporcionar cuidados en casa, producen un aumento de la demanda sobre los servicios sanitarios y sociales. 
Por otra parte, se pide no sólo mejorar la calidad y eficacia en la atención sanitaria, sino también mayor comodidad e intimidad, y mejor información y control del proceso asistencial por el paciente y su familia.

Hay en esta sociedad, como en otras desarrolladas, una progresiva insatisfacción con la salud. Las sociedades avanzadas se sienten hoy más preocupadas por su salud y, en general, más enfermas, que hace cincuenta años. Este fenómeno complejo se ha denominado la «paradoja de la salud», esto es, la sociedad se siente más enferma cuanto mejor es su salud. Hay razones que explican este fenómeno, como unas expectativas en ocasiones carentes de fundamento sobre las capacidades del sistema sanitario y la medicalización de la sociedad.

Pero en lo fundamental este fenómeno de insatisfacción se ha dado como consecuencia del extrañamiento o alienación de la salud. El individuo no se responsabiliza de su salud, que deja en manos de otros. La perdida de este concepto de la salud como algo propio no sólo aumenta la demanda, sino que altera la aceptación del envejecimiento, la enfermedad o la muerte.

Es parte, por tanto, de una política de educación sanitaria el devolver el sentido de la realidad en este extremo e insistir en que la salud no es transferible.

Otro factor de importancia que influye en el incremento de la demanda de cuidados es la tecnología sanitaria.

La tecnología será, sin duda, el componente de los sistemas de salud que más determinará la orientación de las profesiones sanitarios, y el más importante en el incremento del coste sanitario, como señalan estudios recientes de la OCDE.

Hay que contar, además, con otro factor que mueve a la reflexión: la aparición de ciertas prácticas de autodefensa en la profesión médica, motivadas por demandas y fallos judiciales que, aunque afortunadamente no alcanza las cotas de otros países, pueden provocar un uso innecesario y no siempre inocuo de la tecnología.

Todo ello sin mencionar la superespecialización que generan los nuevos conocimientos técnico_científicos, con efectos negativos para la organización del trabajo profesional y para la relación humana entre el paciente y los profesionales.

Hay, por tanto, en sanidad, tensiones por presión de la demanda, por el desarrollo de la tecnología y por tensiones económicas. Tensiones derivadas del hecho demostrado de que la demanda sanitaria superará siempre, en el futuro, a las capacidades de la oferta, y tensiones derivadas de que la inflación de costes en sanidad es superior a la del resto de las áreas económicas. 
Estos problemas no son exclusivos de España. Los servicios sanitarios son objeto de preocupación creciente en las naciones del mundo desarrollado y ocupan cada vez más la atención de los ciudadanos, como revelan las numerosas encuestas de opinión que se han llevado a cabo en este terreno.

El informe Griffiths en el Reino Unido [1983], la Comisión Dekker en Holanda [1987], el Libro Blanco del Reino Unido [1989], el Informe Abril en España [1991] o el The President's Health Security Plan [1993] en los Estados Unidos de América ${ }^{4}$, son ejemplos de numerosas iniciativas y estudios llevados a cabo por encargo de los Gobiernos o de los Parlamentos, incluidos los de los países del Este de Europa. También se han ocupado de este asunto la OMS, la OCDE, la Unión Europea, el Consejo de Europa, así como diversas organizaciones profesionales internacionales.

En general, es común a todos los países la preocupación por los costes, por los problemas de la universalización, por la accesibilidad y la equidad, por la libertad de elección, por la garantía de la calidad y por su eficacia. Todos están buscando formulas para aumentar la motivación de los profesionales, al mismo tiempo que se mejora la satisfacción de los usuarios de estos servicios personales, dentro de los límites económicos.

El debate es creciente, sin que haya respuestas sencillas, ya que, como concluyó la OCDE en un famoso estudio, se trata de «una actividad extremadamente difícil de comprender y delimitar y, por tanto, de gestionan», [Temes y Gil, 1997, pp. 110-112].

\subsection{LOS SISTEMAS DE SEGURIDAD SOCIAL EN LOS PAÍSES DE LA UNIÓN EUROPEA}

Al parecer, la denominación Seguridad Social se debe a Simón Bolívar, quien en 1819 escribía que el sistema de gobierno más perfecto es el que engendra la mayor suma de seguridad social y de seguridad política.

No obstante, la expresión no fue acuñada hasta 1935 por la «Social Security Act» norteamericana, siendo posteriormente definida por Sir Willian Beveridge en 1942, en el segundo y menos conocido de sus informes, como «el conjunto de medidas adoptadas por el Estado contra aquellos riesgos de concreción individual

4. Para ampliar información sobre el Informe Griffiths, la Comisión Dekeker, el Libro Blanco del Reino Unido, el Informe Abril y el The President's Health Security Plan, ver Fernández, J.M.D. [1996], El estado del bienestar, [1996], Comisión de Análisis y Evaluación del Sistema Nacional de Salud, [1991], Ivey [1994], Vallbona [1994], Saltman [1994], Navarro [1993] y López y Puig [1993]. 
que jamás dejaran de presentarse por óptima que sea la situación de conjunto de la sociedad en que vivan» [Temes y Gil, 1997, p. 2].

La conceptuación del termino no puede hacerse, sin embargo, de espaldas a los hechos verdaderos en que se traduce la realidad viva que se denomina Seguridad Social. Del análisis de estos hechos se deriva el concepto de Seguridad Social en el momento presente de su evolución histórica, que pone de manifiesto que:

1. Ante todo, la Seguridad Social es un sistema homogéneo y general de prestaciones, de derecho público y de gestión estatal ordinariamente.

2. Asimismo, es fundamentalmente un sistema de prestaciones.

3. Se trata también de un sistema de situaciones jurídicas que son las que determinan las prestaciones.

4. Supone siempre un aumento de bienestar social para el beneficiario.

5. Es en gran parte un remedio contra el infortunio.

6. Protege sobre todo a quienes desarrollan una actividad laboral como medio fundamental de vida.

En definitiva, la Seguridad Social puede entenderse como «un sistema general y homogéneo de prestaciones de derecho público para el aumento del bienestar social de los ciudadanos»; y en una definición más completa y descriptiva, como «un sistema general Y homogéneo de prestaciones de derecho público para el aumento del bienestar social de quienes se encuentran en determinadas situaciones jurídicas, mediante la redistribución de la riqueza nacional, especialmente dirigida a corregir supuestos de infortunio».

En el panorama conceptual anterior se recogen distintos tipos de Seguridad Social que muestran algunos rasgos propios diferenciados. Así, se observa la existencia de:

- Una Seguridad Social privatista frente a otra publicista, es decir, de gestión privada y estatal respectivamente.

- Seguridad Social Laboral y Seguridad Social Cívica. La primera se limita exclusivamente a los trabajadores, en tanto que la segunda puede extenderse a todos los ciudadanos.

- Seguridad Social causal y contingencial. La diferencia estriba en que la primera atiende a las causas —accidente, enfermedad, etc.mientras que la segunda prescinde de la causa y se fija en la situación concreta establecida o contingencia —invalidez, muerte, etc.- -

- Seguridad Social carencial y no carencial, según que se precise o no un período de carencia para tener derecho a las prestaciones.

- De responsabilidad privada y de responsabilidad pública. 
- Seguridad Social subjetivada y objetivada, estando en esta última la prestación preestablecida, con independencia del perjuicio real, mientras que en la subjetivada la prestación depende del caso concreto que la origine.

Estos distintos tipos de Seguridad Social no suelen darse puros en las leves positivas, sino que se combinan entre sí según las peculiaridades de cada ordenamiento jurídico, predominando unos u otros, aunque con frecuencia coexisten y se mezclan en un sistema positivo determinado.

FIGURA 4.1. Modelos de Seguridad Social.

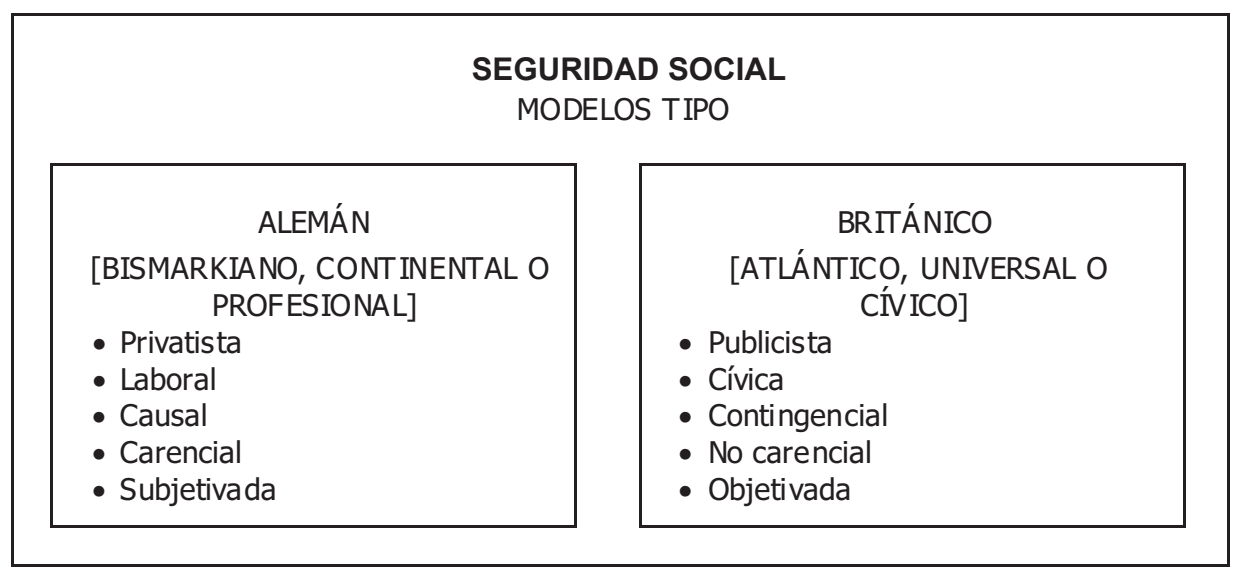

(C) Temes y Gil [1997, p. 3].

No obstante, suelen presentarse agrupados en dos grandes sistemas: de una parte, el que enlaza la Seguridad Social privatista con la laboral, causal, carencial, de responsabilidad privada y subjetivada; y por otra parte, la Seguridad Social publicista, cívica, contingencias, no carencial, de responsabilidad pública y objetivada.

Estos dos modos de organización suponen a grandes rasgos dos tipos diferentes de Seguridad Social: la Seguridad Social como cobertura o aseguradora de riesgos y la Seguridad Social como servicio público.

En la Europa occidental, los sistemas sanitarios pertenecen a los dos grupos citados, modelo «Beveridge» y modelo «Bismarck».

El llamado modelo «Beveridge» o «Sistema Nacional de Salud» se inspira en el informe «Beveridge» de 1942, en el que se formaliza el sistema de organización adoptado por Suecia en los años 30. Este sistema se caracteriza por tener una financiación pública a través de los impuestos, control parlamentario, libertad de acceso para todos los ciudadanos o residentes y gestión, y frecuentemente 
provisión, por parte de los poderes públicos. Los médicos son empleados públicos asalariados o bien remunerados mediante capitación, mientras que los hospitales reciben un presupuesto global limitado.

FIGURA 4.2. Modelo Beveridge.

\begin{tabular}{|c|c|}
\hline \multicolumn{2}{|c|}{$\begin{array}{c}\text { SISTEMAS SANITARIOS EN EUROPA } \\
\text { MODELO «BEVERIDG» - TIPO SERVICIO NACIONAL DE SALUD }\end{array}$} \\
\hline $\begin{array}{l}\text { - } \quad \text { Financiación a través de impuestos. } \\
\text { - } \quad \text { Control gubernamental. } \\
\text { - } \quad \text { Cresupuestos del Estado. } \\
\text { - } \quad \text { Identificactor privado. entre financiación y } \\
\text { provisión. }\end{array}$ & $\begin{array}{l}\text { - Libertad de acceso para todos. } \\
\text { - Importante inversión del Estado en la } \\
\text { gestión. } \\
\text { - Médicos asalariados o por capitación. } \\
\text { Algunos pagos directos por parte de } \\
\text { los usuarios. }\end{array}$ \\
\hline $\begin{array}{r}\text { arca, España, Finlandia, } \\
\text { Reinc }\end{array}$ & $\begin{array}{l}\text { Irlanda, Italia, Noruega, Portugal, } \\
\text { y Suecia. }\end{array}$ \\
\hline
\end{tabular}

(C) Ernst \& Young [1996, p. 187].

Todos los países del norte de Europa —Dinamarca, Finlandia, Irlanda, Noruega, Suecia, Reino Unido- mantuvieron o adoptaron este modelo después de la Segunda Guerra Mundial. Los países del sur de Europa - Grecia, Italia, Portugal, España - se unieron a este grupo en los años 80. Constituye, por lo tanto, en la actualidad el modelo predominante en los países avanzados.

FIGURA 4.3. Modelo Bismarck.

\section{SISTEMAS SANITARIOS EN EUROPA \\ MODELO «BISMARCK» - SISTEMA DE SEGUROS SOCIALES}

- Financiados por cuotas obligatorias pagadas por empresarios y trabajadores o a través de los impuestos.

- Los recursos financieros van a parar a los «fondos», que son entidades no gubernamentales reguladas por ley y que gestionan estos recursos.

- Los fondos contratan hospitales, médicos de familia, etc., para que provean de los servicios a los aseguradores mediante contratos basados en un presupuesto 0 mediante pago por acto.

Alemania, Austria, Bélgica, Francia y Países Bajos.

(C) Ernst \& Young [1996, p. 188]. 
El modelo «Bismarck», también llamado «sistema de seguros sociales», se inspiró en la legislación social alemana. Bismarck, abandonando la actitud abstencionista típica del estado liberal, instituyó un régimen de seguros sociales en favor de los trabajadores de la industria económicamente débiles. En 1883 instauró el primer seguro social, el de enfermedad, en 1884 el de accidentes de trabajo, y en 1889 el de vejez-invalidez.

TABLA 4.3. Fuentes de financiación de la asistencia sanitaria de la Seguridad Social —en porcentaje-.

\begin{tabular}{|c|c|c|c|c|c|c|}
\hline Fuentes $^{1}$ & 1979 & 1982 & 1991 & 1994 & 1995 & 1996 \\
\hline Impuestos generales & 5,5 & 14,9 & 66,1 & 70,2 & 77,3 & 82,6 \\
\hline Contribuciones S.S. & 90,2 & 82,8 & 29,4 & 27,1 & 20,5 & 14,9 \\
\hline Otros ingresos ${ }^{2}$ & 4,3 & 2,3 & 4,6 & 2,7 & 2,2 & 2,5 \\
\hline Total $^{3}$ & 100,0 & 100,0 & 100,0 & 100,0 & 100,0 & 100,0 \\
\hline
\end{tabular}

(C) NERA [1997, p. 183] y Temes y Gil [1997, p. 95].

TABLA 4.4. Cobertura sanitaria en España, 1993.

\begin{tabular}{|l|c|c|c|}
\hline \multicolumn{4}{|c|}{ Porcentaje cubierto } \\
\cline { 2 - 4 } & $\%$ - 15 años & $\%>15$ años & $\%$ del total \\
\hline Seguridad Social & 97,3 & 93,8 & 94,7 \\
\hline Beneficencia & 0,3 & 0,2 & 0,2 \\
\hline Mutualidades/Seguridad Social & 1,8 & 2,5 & 2,4 \\
\hline Mutualidades/Seguro privado & 2,7 & 2,0 & 2,1 \\
\hline Seguro privado individual & 5,9 & 6,4 & 6,3 \\
\hline Seguro de empresas & 0,6 & 1,5 & 1,3 \\
\hline Seguro capitativo & 0,0 & 0,1 & 0,1 \\
\hline Médico privado & 0,1 & 0,5 & 0,4 \\
\hline Desconocido & 0,8 & 1,0 & 0,9 \\
\hline
\end{tabular}

(C) NERA [1997, p. 188]. 
Este sistema se caracteriza porque su financiación se realiza mediante cuotas obligatorias pagadas por las empresas y los trabajadores a unos fondos públicos. Los ciudadanos que no tienen acceso a este tipo de fondos son cubiertos bien mediante el sistema impositivo o bien por seguros privados. Los cuidados médicos son dispensados por los llamados médicos autónomos — profesionales liberales-, pagados por acto médico, mientras que los hospitales reciben presupuestos globales.

\subsection{HISTORIA DEL SISTEMA SANITARIO EN ESPAÑA}

La evolución del sistema sanitario español está ligada con la historia y desarrollo de la Seguridad Social en España. La asistencia sanitaria de la Seguridad Social adquiere un protagonismo decisivo a partir de los años 60 , ante el escaso desarrollo de otras redes tanto de beneficencia como de sanidad privada.

A diferencia de lo ocurrido en la mayoría de los países, la Seguridad Social española desarrolla una extensa red de Centros y Servicios propios para la asistencia de medicina general, ambulatoria de especialidades y hospitalaria, a la vez que fue ampliando la cobertura de la población — 53,1\% en 1966 al 81,7\% en 1978-.

La función pública de sanidad atribuida al Estado, cuyo origen se remonta a 1855, sufre escasas variaciones hasta 1977, correspondiéndole atender los problemas sanitarios que afectan a la colectividad y recayendo la responsabilidad en la Dirección General de Sanidad dependiente del Ministerio de la Gobernación.

Las Corporaciones locales, a cuyo cargo estaba la asistencia de beneficencia, contaban con centros hospitalarios que fueron descapitalizándose progresivamente.

Como respuesta a lo previsto en la Constitución Española de 1978, la promulgación de la Ley General de Sanidad supone el reconocimiento del derecho a la asistencia sanitaria de todos los ciudadanos, integrando los servicios sanitarios de todas las Administraciones públicas y estableciendo el esquema del Sistema Nacional de Salud.

En el ámbito de la cobertura de la población se produce un cambio cualitativo en 1989 al extenderse la misma, sin carácter contributivo, a los españoles sin recursos económicos suficientes y desapareciendo, por tanto, la beneficencia.

A partir de los años 80, tiene lugar una profunda reforma en la Atención Primaria con la creación de los Centros de Salud, en los que se atiende de forma integral los problemas de salud. 
Los centros hospitalarios dependientes de las Corporaciones locales, así como los de las Universidades, se van integrando junto con los Hospitales de la Seguridad Social en una red pública única, en el ámbito de los Servicios Regionales de Salud de las diferentes Comunidades Autónomas.

\subsection{INTRODUCCIÓN A LA LEY GENERAL DE SANIDAD}

La creación del Sistema Nacional de Salud, que lleva a cabo la Ley General de Sanidad, y su posterior consolidación hacen que el debate sobre el «modelo sanitario», que era el punto de atención relevante antes de dicha Ley, haya dado paso a debates sobre otros aspectos más concretos, que aunque sean objeto de arduas disputas y teorizaciones políticas y sociales internas, en realidad son cuestiones que se comparten con todos los países del entorno social y económico europeo.

La asignación de recursos al sistema sanitario, la evaluación de la eficacia de los servicios de salud y la búsqueda de la estructura y de la organización más adecuada para el funcionamiento de los servicios sanitarios, son elementos comunes del debate sobre la sanidad en todos los países occidentales desarrollados. También en España.

Así pues, La Ley General de Sanidad es el punto de partida del Sistema Nacional de Salud, que no cabe duda de que es un gran logro de la sociedad española.

La Constitución establece derechos fundamentales de los ciudadanos, pero no establece el camino para hacerlos efectivos. Son las leyes las que posteriormente deben definir conceptualmente que, es lo que comprende tal derecho, debiendo desarrollar las acciones concretas necesarias para su consecución.

La Constitución reconoce expresamente el derecho de todos los ciudadanos a la protección de la salud —art. 43.1 - y transmite la responsabilidad de garantizar este derecho a los poderes públicos —art. 43.2-.

Se trata, por tanto, de preguntarse cuál es el significado que tiene la protección de la salud y cuáles son las responsabilidades concretas que los poderes públicos contraen, como garantes de tal derecho. Podemos decir que el derecho a la protección de la salud significa el deber de la defensa de la salud, en toda su dimensión, como el bien más preciado que posee el individuo y la comunidad en que se inserta.

Pues bien, para ello se promulga la Ley General de Sanidad, en la que, como reconoce su propio Preámbulo, la directriz sobre la que descansa toda la reforma 
es la creación de un Sistema Nacional de Salud, siendo el eje del modelo que la Ley adopta las Comunidades Autónomas.

A pesar de que muchos opinan que la Constitución no otorga un lugar relevante a la sanidad, al no incluirla en el Título I, en el que se regulan los derechos básicos de los españoles que se desarrollan a través de ley orgánica, no debemos olvidar que la salud es el derecho más importante de los que goza el ser humano, ya que sin ella sería imposible el ejercicio del resto de los derechos de la persona.

La Constitución hace referencia expresa a la sanidad, no sólo en el artículo 43, sino también en los artículos 148.1.21 y 149.1.16. Además, los artículos 41 y 149.1.17 se refieren a funciones y actividades de carácter sanitario, y los artículos $10,14,15,18,45,47,49$ y 51 contienen referencias, que manifiestan la preocupación de esta norma por la salud y la sanidad.

\subsubsection{LA LEY GENERAL DE SANIDAD}

La Ley 14/1986 de 25 de abril, General de Sanidad _LGS_, crea un sistema sanitario público: el Sistema Nacional de Salud —SNS_- cuyo eje son las Comunidades Autónomas, ya que el SNS se concibe como «el conjunto de Servicios de Salud de las Comunidades Autónomas convenientemente coordinados».

La LGS establece dos niveles asistenciales: atención primaria y atención especializada -este último con dos escalones: servicios convencionales y servicios de referencia - y hace especial hincapié en la integración efectiva de los servicios asistenciales públicos y en particular, dada su importancia, los de la Sanidad Nacional y los de la Seguridad Social.

Por otra parte, dispone una distribución en las competencias de las Administraciones Públicas, reservando al Estado las facultades de dirección en lo básico y las de coordinación, mientras que los servicios sanitarios quedan bajo la responsabilidad de las Comunidades Autónomas, que sustituyen en este campo a las Corporaciones locales, si bien éstas mantienen sus competencias tradicionales en materia de sanidad e higiene del medio ambiente.

Asimismo, la Ley diseña una ordenación novedosa del sistema sanitario público, donde las Áreas de Salud se configuran como las estructuras fundamentales del SNS, responsabilizándose de los centros y establecimientos y de todas las prestaciones a desarrollar en ellos.

Para conseguir la máxima operatividad y eficacia, las Áreas se dividen en Zonas Básicas, donde desarrollan su actividad los equipos de Atención Primaria. 
La Ley establece la facultad de libre elección de médico en la atención primaria del Área de Salud —art. 14-, la creación de una red integrada de hospitales del sector público y la vinculación al SNS de los hospitales del sector privado que lo soliciten, cuando las necesidades asistenciales lo justifiquen —art. 66-.

También se reconoce el derecho al ejercicio libre de las profesiones sanitarias y libertad de empresa en el sector sanitario, conforme a la Constitución —arts. 88 y 89 -.

Otros aspectos importantes de la Ley son: la integración de las actividades de salud mental —art. 20 - en el sistema sanitario general y la extensión de la cobertura sanitaria de la Seguridad Social a las personas no incluidas en la misma o cuando se trata de personas sin recursos económicos suficientes — art. 80—.

En resumen, los componentes básicos del SNS son:

- La extensión de la cobertura sanitaria pública a toda la población. Consiste en la universalización de los servicios sanitarios para todos los ciudadanos en condiciones de igualdad, con independencia de las circunstancias personales o sociales.

- La equidad en el acceso a las prestaciones sanitarias. Hacer accesibles los recursos sanitarios, de forma que no se produzcan discriminaciones por razones geográficas. Es decir, equidad en la distribución de los recursos.

- La solidaridad. El sistema se fundamenta en una doble solidaridad: la propia de todos los sistemas impositivos progresistas — paga más el que más tiene- y la adicional de los sanos en relación con los enfermos. Contribuyen todos los ciudadanos, para que se atienda a los que lo necesiten en el momento en que lo precisen.

- La financiación pública. Se financia en su mayor parte a través de los ingresos del Estado, a partir de la modificación del sistema de financiación de la asistencia sanitaria introducida en la Ley de Presupuestos Generales del Estado para 1989, que asegura el derecho de todos a la protección de la salud, tal y como se recoge en la Ley General de Sanidad.

- La coordinación y, en su caso, la integración de todos los recursos sanitarios públicos en un dispositivo único, para asegurar un sistema coherente, armónico y eficaz.

- La integración de políticas de promoción de la salud y de prevención de la enfermedad, junto a prestaciones médicas y farmacéuticas.

- La descentralización en las Comunidades Autónomas. 


\subsection{EVOLUCIÓN DEL MODELO DE SEGURIDAD SOCIAL EN ESPAÑA}

En España se puede encontrar antecedentes de protección social muy antiguos, que en el siglo XIX empiezan a consolidarse con instituciones públicas para los desposeídos y sociedades voluntarias de socorros mutuos promovidas por los sindicatos obreros.

Sin embargo, la Seguridad Social obligatoria suele seguir en todos los países a la industrialización, lo que ayuda a explicar por que en España, con un desarrollo industrial tardío, la Seguridad Social no alcanza la importancia cuantitativa que tiene en otros países occidentales hasta finales de los años 70 .

No obstante, el desarrollo institucional se había venido produciendo a lo largo de todo el siglo, y la forma como se lleva a cabo condicionar la situación del momento e incluso la evolución futura.

Ya desde principios de siglo, con la Ley de accidentes de trabajo de 30 de enero de 1900, España se inicia por la vía de seguros obligatorios, con financiación básicamente contributiva, adoptando, por tanto, el modelo profesional o bismarckiano. Esta tendencia se consolida después de la Guerra Civil, con un desarrollo, paulatino pero acumulativo, en el que se mantiene un nivel reducido de protección y en el que todavía permanecen excluidos colectivos muy numerosos de ciudadanos.

Sin embargo, a pesar de la ampliación, tanto de los colectivos protegidos como de la acción protectora, el esquema de protección resultaba insuficiente en los años 60.

Con la aprobación de la Ley de Bases de la Seguridad Social de 28 de diciembre de 1963, cuyo texto articulado entra en vigor el 1 de enero de 1967, se produce un importante cambio cualitativo, con la superación de los esquemas propios del Seguro y la introducción de un concepto moderno de Seguridad Social.

Los principios de la Ley de Bases son los siguientes:

1. Tendencia a la unidad.

2. Participación de los interesados en el gobierno de las entidades gestoras.

3. Supresión del ánimo de lucro en la gestión.

4. Consideración conjunta de las situaciones y las contingencias protegidas.

5. Aumento de las aportaciones estatales en la financiación.

6. Preferente preocupación por la prevención y rehabilitación. 
En líneas generales, aunque con la Ley seguía manteniéndose el carácter profesional por cuanto las prestaciones económicas van orientadas a sustituir los ingresos de trabajo perdidos, se perfila una voluntad de extender la protección a los distintos colectivos de trabajadores.

Cinco años más tarde la Ley 24 de 1972 de Financiación y Perfeccionamiento de la Acción Protectora del Régimen General de la Seguridad Social sentó las bases para un crecimiento rápido de las cotizaciones y prestaciones por la progresiva aproximación de las bases a los salarios reales.

A mediados de los años 70 dos fenómenos ajenos a la propia Seguridad Social influyeron poderosamente en su evolución:

- La restauración de la democracia, lo que facilitó que los ciudadanos reivindicasen mejores prestaciones, poniéndose en evidencia necesidades no cubiertas.

- La crisis económica, que se dejaba ya sentir de forma indudable.

Estos dos factores originaron importantes desequilibrios en el Sistema, tanto económicos como de gestión de las prestaciones.

Por otra parte, el Texto Constitucional, aprobado el 31 de octubre de 1978, establecía en su artículo 41 el derecho de todos los ciudadanos a la Seguridad Social; en el artículo 43, el derecho de todos a la protección de la salud; y en el 149, que corresponde al Estado la legislación básica y el régimen económico de la Seguridad Social, sin perjuicio de la ejecución de sus servicios por las Comunidades Autónomas que en lo sucesivo se establecieran.

Por estos motivos, entre 1977 y 1979, se llevó a cabo una profunda reorganización institucional y gestora, reduciéndose el número de entidades y especificándose sus funciones. Se introducen varias formas de control: el parlamentario, a través sobre todo de la aprobación previa del presupuesto anual, el de la Intervención y el Tribunal de Cuentas, y el de los Sindicatos libres y Organizaciones Empresariales, a través de los Consejos de las Entidades Gestoras.

Estas Entidades se crearon por el Real Decreto-Ley 36/1978, de 16 de noviembre, sobre gestión institucional de la Seguridad Social, la Salud y el Empleo, en sustitución del INP y de las numerosas Mutualidades y Servicios Comunes que existían en aquel momento. En un intento de simplificación del sistema de Entidades Gestoras, éstas quedaron reducidas a tres.

- INSS: Para gestionar las prestaciones económicas.

- INSALUD: Para gestionar las prestaciones sanitarias.

- INSERSO: Para gestionar las prestaciones sociales. 
Otras medidas legislativas tomadas para subsanar la situación de la Seguridad Social fueron las siguientes:

- La Ley Básica de Empleo.

- Ley 31/84 de 2 de agosto de protección por desempleo.

- Ley 26185 de 31 de julio de medidas urgentes para racionalización de la estructura y de la acción protectora de la Seguridad Social.

\subsection{EVOLUCIÓN DEL SISTEMA SANITARIO ESPAÑOL}

Como reconoce la propia Exposición de Motivos de la Ley General de Sanidad, «de todos los empeños que se han esforzado en cumplir los poderes públicos desde la emergencia misma de la Administración contemporánea, tal vez no haya ninguno tan reiteradamente ensayado ni con tanta obstinación frustrado como la reforma de la sanidad» [Temes y Gil, 1997, p. 6].

La sanidad se ha intentado reformar permanentemente. De los múltiples intentos habidos, muy pocos han cuajado, especialmente porque los conocimientos técnicos no eran los adecuados, como sucedió con el primer intento de intervención pública en los problemas de salud, que constituyó el abortado proyecto de Código Sanitario de 1822.

La primera norma de carácter general sobre el sector sanitario es la Ley de 28 de noviembre de 1855, que establece un sistema de prestaciones asistenciales sobre la base del libre ejercicio profesional de los médicos. Esta Ley regula unos órganos de desarrollo de acciones sanitarias dirigidas a la atención de los problemas de salud de la colectividad: sistema cuarentenal, baños termales, higiene pública, vacunaciones, sanidad mortuoria, etc. Las competencias sanitarias se atribuyen a la Dirección General de Sanidad -Ministerio de la Gobernación-, creada muy pocos años antes, a los gobernadores y a los alcaldes.

Casi 50 años después, a lo largo de los cuales hubo varios intentos de reformar la anterior Ley, por Real Decreto de 12 de enero de 1904, se aprueba la Instrucción General de Sanidad Pública, que mantiene el mismo reparto de competencias diseñado en la Ley de 1855, cambiando solamente el nombre de la Dirección General de Sanidad por el de Inspección General de Sanidad.

En esta Instrucción se regula un dispositivo de higiene al nivel de Estado y se reglamenta pormenorizadamente la higiene municipal y la sanidad e higiene provincial. Se trata de una norma progresista, que aborda la doble organización profesional — profesiones sanitarias libres y oficiales-, con sus respectivas 
obligaciones, y, en la que aparecen, por primera vez, las organizaciones corporativas estructuradas en Colegios profesionales provinciales.

En 1925, aparecen dos normas reguladoras del sector sanitario: los Reglamentos de Sanidad Municipal y Provincial. En éstos se regulan, exhaustivamente, las competencias sanitarias de las Diputaciones, Partidos Judiciales y Municipios.

La II República Española, en el año 1934, aprueba una Ley de Coordinación de Servicios Sanitarios, que tuvo una vida muy corta, ya que fue derogada en parte por la propia República y en su totalidad después de la Guerra Civil.

Posteriormente, con una vigencia que duró hasta la publicación de la actual Ley General de Sanidad, en 1944 se aprueba la Ley de Bases de Sanidad Nacional.

Esta Ley asume el mismo esquema de organización que las normas de 1855 y 1904, con una Dirección General de Sanidad fortalecida, como órgano supremo. Se afianza, aún más, la separación entre la sanidad colectiva, responsabilidad del Gobierno central, y la sanidad individual, responsabilidad de las Corporaciones locales, a través de un esquema benéfico de facultativos titulares, encargados de la atención de las personas consideradas «pobres», que dependía orgánicamente de las Diputaciones. El Estado se encargaba, mediante dispensarios y hospitales, de la cobertura de las enfermedades consideradas como lacras sociales, como por ejemplo: tuberculosis, lepra, paludismo, etc.

También dedica la Ley de Bases uno de sus preceptos a las relaciones con el Seguro Obligatorio de Enfermedad —SOE—, creado dos años antes. En efecto, la Ley de 14 de diciembre de 1942 crea el Seguro Obligatorio de Enfermedad, integrado en el Instituto Nacional de Previsión. Consiste en un sistema de cobertura de riesgos sanitarios, basado en una cuota vinculada al trabajo, que se desarrolló enormemente, y en muchas ocasiones independientemente de la propia Ley, en los años 60 y 70, principalmente por la expansión económica en esos períodos.

El Seguro Obligatorio de Enfermedad, desde su creación y su reestructuración mediante el Decreto por el que se aprueba el Texto Refundido de la Ley General de la Seguridad Social, fue asumiendo mayor número de patologías e incluyendo mayor número de personas y colectivos dentro de su esquema. Era el gestor autónomo de una gran estructura, que constituía la red sanitaria más importante del país.

Así, desde principios de los años 40 e incluso antes, se vinieron creando subsistemas sanitarios diferentes e independientes. Principalmente: la red dependiente de las Corporaciones locales —Diputaciones y Municipios_, la 
red dependiente del Estado y la red de la Seguridad Social. Sus objetivos, sin ser diferentes, tampoco fueron complementarios, por lo que progresivamente fueron produciéndose solapamientos, con la correspondiente ineficacia y desorganización.

En definitiva, hasta la Ley General de Sanidad, el sistema sanitario español se caracterizaba por estar constituido por un gran número de redes asistenciales, que en muchas ocasiones, solapaban sus funciones. Hasta 19 centros directivos de diferentes Ministerios, tenían competencias en la materia.

Como hemos visto, su referencia normativa básica la constituían la Ley de 14 de diciembre de 1942, que implantó el Seguro Obligatorio de Enfermedad, dentro del sistema de protección social gestionado por el Instituto Nacional de Previsión, y la Ley de Bases de Sanidad Nacional de 1944, que atribuyó a las Administraciones territoriales competencias en materia de higiene pública, prevención y asistencia a la población marginada, y que se consumía progresivamente sin ser derogada.

La asistencia sanitaria de la Seguridad Social era de base mutualista, orientación reparadora, cobertura no universal y financiación por cuotas. Sus recursos estaban geográficamente mal distribuidos, concentrándose en grandes centros hospitalarios, ubicados en las principales capitales de provincia, y pequeños e insuficientes hospitales en el resto. La gestión adolecía de importantes carencias, que se traducían en un tratamiento de los recursos más administrativo que gestor.

Además, existía una amplia red, muy descapitalizada, de centros asistenciales, generales o monográficos, hospitalarios o no, dependientes de Ayuntamientos, Diputaciones y Universidades Públicas.

Las funciones preventivas y algunas asistenciales se orientaban preferentemente a determinadas enfermedades de particular trascendencia social, sin nexo con el resto de los sistemas en la formulación de las respectivas políticas sanitarias.

En 1977 se creó por primera vez, desde la II República, un Ministerio de Sanidad y Seguridad Social, que pasó a ser de Trabajo, Sanidad y Seguridad Social en mayo de 1981, y de Sanidad y Consumo en diciembre de ese mismo año.

En noviembre de 1978 —ver el citado Real Decreto-Ley 36/1978desaparece y se divide el Instituto Nacional de Previsión, del que dependía la asistencia sanitaria de la Seguridad Social. Al Instituto Nacional de la Salud -INSALUD— se le asigna la gestión de la asistencia sanitaria.

En 1979 se inicia la transferencia de competencias de promoción, prevención y planificación territorial sanitaria a los Entes preautonómicos y Comunidades 
Autónomas —ya concluidos-, y en julio de 1981 se inicia el proceso de transferencias de la gestión de la asistencia sanitaria de la Seguridad Social, con la Generalitat de Catalunya.

En 1984 se inicia la reforma de la Atención Primaria de Salud mediante la promulgación del Real Decreto 137/1984, de estructuras básicas de salud. Hasta 1984 la asistencia primaria se prestaba por médicos generales y pediatras, en centros con insuficiencias técnicas y arquitectónicas, que trabajaban de modo individualizado, con una dedicación de dos horas y media diarias.

La reforma de la Atención Primaria de Salud ha hecho posible que se constituyan equipos de Atención Primaria integrados por médicos generales, pediatras, personal de enfermería y otros profesionales sanitarios, que trabajan en Centros de Salud, que dirigen sus actividades tanto hacia la demanda sanitaria como hacia las necesidades de salud de la zona que tienen adscrita, en jornada de 40 horas semanales.

En 1995 el 75\% de la población —en el territorio del INSALUD— recibía asistencia sanitaria a través de equipos de Atención Primaria. La asistencia estaba basada en una concepción integral de la salud, y la cartera de servicios incluya actividades de promoción, prevención y rehabilitación, además de las propiamente asistenciales.

En 1986 se aprueba la Ley General de Sanidad por la que se establece un cambio trascendente en la filosofía política de la asistencia médico-sanitaria, ya que transformó un sistema de Seguridad Social en un modelo de Sistema Nacional de Salud en el que se integran el resto de las redes asistenciales existentes.

Históricamente, la financiación de la asistencia sanitaria estaba a cargo de los Presupuestos de la Seguridad Social. En 1989 se inicia la modificación del modelo, financiándose en un 30\% por cuotas de la Seguridad Social y en un $70 \%$ a través de los Presupuestos Generales del Estado.

En 1975 el gasto sanitario público representaba el 3,8\% del PIB, que se ha elevado en 1995 al 5,7\% —el gasto sanitario total en 1975 era el 4,9\% del PIB y en 1995 el 7,3\%-.

El presupuesto de sanidad se ha quintuplicado, pasando de los 695.000 millones de pesetas del año 1982 a 3,5 billones en 1996.

En 1975 el 77\% de la población estaba incluida en la Seguridad Social. En 1995 el 98,5\% de la población está cubierta por el Sistema Nacional de Salud, lo que representa un incremento de aproximadamente 8,5 millones de personas.

Aunque desde el año 1972 había convocatorias anuales de plazas de residentes de manera aislada, hasta 1978 la formación de especialistas no se 
encontraba reglada en el ámbito nacional, estando vinculada a la Universidad y a la práctica asistencial.

En 1978 se modifica mediante Real Decreto el procedimiento para la obtención del título de especialista, que hasta entonces estaba regulado por la Ley de Especialidades Médicas de 1955.

Entre 1980 y 1994, la oferta anual de formación de especialistas en el Sistema MIR se ha multiplicado por dos y medio —en 1980 se convocaron 2077 plazas y 5000 en 1995-.

La introducción de la investigación médica en los hospitales ha experimentado un importante desarrollo a partir de 1980, fecha en la que se transforma el Fondo de Descuento Complementario, del INP, en el Fondo de Investigaciones Sanitarias de la Seguridad Social.

A partir de la Ley General de Sanidad se crea, como órgano de apoyo científico-técnico del Sistema Nacional de Salud, el instituto de Salud Carlos III, con carácter de organismo autónomo, adscrito al Ministerio de Sanidad y Consumo, en el que se integran la Escuela Nacional de Sanidad y el Fondo de Investigaciones de la Seguridad Social.

Por todo lo anterior, en la historia del sistema sanitario español hay que referirse a dos etapas: antes y después de la promulgación de la Ley General de Sanidad.

Antes de la Ley General de Sanidad coexistían dentro del sistema público múltiples redes asistenciales sin coordinación entre ellas:

- Al Estado le correspondía la función pública de sanidad, desarrollando una red de hospitales, dirigida a enfermedades de trascendencia social - por ejemplo: antituberculosos-.

- La asistencia sanitaria de la Seguridad Social, que dependía del Ministerio de Trabajo, con su propia red asistencias.

- La asistencia de beneficencia, que dependía principalmente de las Corporaciones locales, que a su vez habían creado Hospitales Generales. De ellas dependía también la atención psiquiátrica - Hospitales Psiquiátricos-.

- Otras redes asistenciales, cuyas competencias se atribuían a distintos Departamentos del Gobierno: la Sanidad Militar, Hospitales Universitarios, y Sanidad Penitenciaria.

Después de la Ley General de Sanidad, todas las redes se integran en el Sistema Nacional de Salud. 


\subsection{EL PROCESO DE TRANSFERENCIAS SANITARIAS}

La legislación general en materia de transferencias está formada por la Constitución Española, norma suprema e iniciadora del proceso, los Estatutos de Autonomía, que establecen el marco de competencia autonómico y definen sus órganos de autogobierno y los Reales Decretos de Normas de Traspaso de Servicios y Funcionamiento de las Comisiones Mixtas, que, para cada Comunidad Autónoma, establecen el cauce formal de las transferencias.

La distribución de competencias que establece el Título VIII de la Constitución, en cuanto a las funciones sanitarias, obliga a distinguir tres campos para considerar el proceso de transferencias. Estos tres campos concretos se refieren a la sanidad e higiene, la asistencia sanitaria de la Seguridad Social y la Administración Institucional de la Sanidad Nacional —AISNA-.

En el inicio del proceso de transferencias, la posibilidad de asumir competencias por parte de las Comunidades Autónomas, en relación con estos tres apartados, se ve afectada por la vía utilizada, por cada una de ellas, para acceder a su autonomía.

En efecto, las Comunidades Autónomas que utilizaron la vía del artículo 143 de la Constitución sólo podían asumir, de entrada, a través de sus Estatutos, las competencias recogidas en el artículo 148.1, que incluye en su apartado 21, la sanidad e higiene y la Administración Institucional de la Sanidad —AISNA—.

Por el contrario, la asistencia sanitaria de la Seguridad Social se vinculaba en el artículo 149.1.17 y podía ser asumida únicamente por las Comunidades que accedieron a su autonomía por el art. 151.

\subsubsection{TRANSFERENCIAS EN MATERIA DE SANIDAD}

Las transferencias en materia de sanidad se inician con las Comunidades Autónomas de Catalunya y el País Vasco. Como era lógico, el tema principal de discusión fue la delimitación de las competencias y funciones a transferir, teniendo en cuenta que, como era habitual en esta primera etapa preautonómica, en los Reales Decretos de Traspasos no figuraban los medios personales, materiales y presupuestarios que se transferían. Puede señalarse que el texto de estos primeros Reales Decretos, en los que se describían las funciones transferidas, sirvió con posterioridad como modelo, seguido práctica y literalmente por las demás Comunidades Autónomas e incluso después por las Comisiones Mixtas de Transferencias de las distintas Comunidades Autónomas, una vez constituidas como tales. Debe tenerse en cuenta que, cuando se iniciaron las transferencias, el 
Ministerio, que se llamaba de Sanidad y Seguridad Social, tenía una estructura periférica que respondía a cometidos y materias muy diversas, lo que dificultó la delimitación de los medios personales y materiales a traspasar.

Actualmente, el proceso de transferencias en materia de sanidad e higiene ha concluido habiéndose formalizado básicamente a través del siguiente Real Decreto, para Catalunya: RD 2210/1979, de 7 de septiembre, sobre transferencia de competencias de la Administración del Estado a la Generalitat de Catalunya, en materia de agricultura, cultura, sanidad y trabajo.

\subsubsection{DISTRIBUCIÓN DE COMPETENCIAS SANITARIAS}

\subsubsection{COMPETENCIAS DEL ESTADO}

\section{Sanidad exterior}

La Ley General de Sanidad, de acuerdo con lo definido en la Constitución, establece que la sanidad exterior y las relaciones y acuerdos internacionales corresponden al Estado con competencia exclusiva, definiendo aquella —art. 38.2 - del siguiente modo: «Son actividades de Sanidad Exterior todas aquellas que se realicen en materia de vigilancia y control de los posibles riesgos para la salud derivados de la importación, exportación o tránsito de mercancías, y del tráfico internacional de viajeros». Además, la propia Ley se refiere al principio de colaboración entre Administraciones en su Disposición final octava, con arreglo a la cual el Gobierno, mediante Real Decreto, adopta las medidas necesarias para la actuación conjunta de varias Administraciones públicas, a efectos de sanidad exterior y para reconocer validez a las actuaciones de los servicios técnicos de las Comunidades Autónomas. Esta previsión se llevó a cabo mediante el Real Decreto 1418/1986, sobre funciones en materia de sanidad exterior.

\section{Bases de la sanidad}

El concepto de bases ha sido definido a través de una abundante jurisprudencia del Tribunal Constitucional, incluso sobre el tema concreto sanitario, aunque no entraremos a analizarlas por no ser éste el lugar adecuado. Se recoge esta competencia en el artículo 149.1.16 de la Constitución y, posteriormente, la Ley General de Sanidad, en su artículo 2, manifiesta que tiene la condición de norma básica en el sentido previsto en la Constitución y que será de aplicación en todo el territorio del Estado, excepto determinados artículos y apartados, para los que la Ley constituirá derecho supletorio. 
La Ley, en su artículo 40, establece, igualmente, una serie de competencias del Estado en determinados ámbitos, referidas, en todo caso, a bases de la sanidad.

\section{La coordinación general de la sanidad}

La Constitución, en su artículo 149.1, recoge tres casos en los que la coordinación queda reservada al Estado como competencia exclusiva: economía -149.1.13—, investigación científica y técnica -149.1.15- y sanidad -149.1 .16 -

La Ley General de Sanidad hace referencia a la coordinación general sanitaria en los artículos 70 y siguientes, previéndose en el artículo 73 que se ejercerá por el Estado que aprobará sus criterios, fijando medios y sistemas de relación para facilitar la información recíproca, la homogeneidad técnica y la acción conjunta de las Administraciones públicas sanitarias en el ejercicio de sus respectivas competencias, de tal modo que se logre la integración de sus actos parciales en la globalidad del Sistema Nacional de Salud. El Plan Integrado de Salud, a confeccionar por la Administración sanitaria, deberá tener en cuenta los criterios de coordinación general elaborados por el Gobierno y recoger en un documento único los planes estatales, los planes de las Comunidades Autónomas y los planes conjuntos en su caso.

\section{Legislación sobre productos farmacéuticos}

La competencia sobre productos farmacéuticos es exclusiva del Estado, entendiéndose que en este caso la exclusividad no se refiere sólo a la básica, sino que comprende las normas reglamentarias. La Constitución reservó al Estado la legislación sobre productos farmacéuticos, entendiendo, como ha recordado el Tribunal Constitucional, que abarca toda la función normativa. Una vez sentado este principio, el problema reside en definir que, se entiende por productos farmacéuticos. La Ley ha interpretado que las competencias de legislación en sentido amplio y exclusivo se refieren sólo al producto en sí y a la fase de producción del mismo; en las demás fases, la Administración del Estado únicamente tiene la competencia de fijación de bases —art. 40 LGS —.

\section{La alta inspección}

Aunque podría considerarse implícita, la Constitución no hace referencia expresa a la Alta Inspección del Estado. Por el contrario, todos los Estatutos de Autonomía recogen expresamente esta función, como competencia estatal de garantía del cumplimiento correcto de las competencias autonómicas. 
Por su parte, el Tribunal Constitucional se ha pronunciado sobre esta competencia estatal, referida concretamente a la sanidad, en las sentencias 32/83 y 42/83, manifestando que la Alta Inspección es una manifestación de las funciones estatales de vigilancia. Estas sentencias se dictaron en relación con los Reales Decretos 2824/81 y 2825/81, sobre coordinación y planificación sanitaria y registro sanitario de alimentos, que fueron impugnados ante el Tribunal Constitucional y declarados inconstitucionales en parte.

Posteriormente, la Ley General de Sanidad, teniendo en cuenta la doctrina sentada por el Tribunal Constitucional, dedica su artículo 43 a la Alta Inspección, determinando que sea ejercida por el Estado como «función de garantía y verificación del cumplimiento de las competencias del Estado y de las Comunidades Autónomas en materia de sanidad, de acuerdo con lo establecido en la Constitución y en las leyes».

Las actividades que la Ley establece después de esta definición entendemos que se refieren exclusivamente a la función de garantía encomendada, sin intervenir en el control directo de la actividad autonómica.

\subsubsection{COMPETENCIAS DE LAS COMUNIDADES AUTÓNOMAS}

El artículo 41 de la Ley General de Sanidad dispone que las Comunidades Autónomas ejercerán las competencias asumidas en sus Estatutos y las que el Estado les transfiera o, en su caso, les delegue, y que las decisiones y actuaciones públicas previstas en ella que no se hayan reservado expresamente al Estado se entenderán atribuidas a las Comunidades Autónomas. Debe precisarse que las competencias las asumen las Comunidades Autónomas por la Constitución y sus respectivos Estatutos de Autonomía y que los Reales Decretos de transferencias no traspasan competencias, que se supone que ya están asumidas, sino únicamente los medios para hacerlas efectivas. Este es un error terminológico muy frecuente, que procede de cuando las Comunidades Autónomas no estaban constituidas como tales y no tenían Estatuto de Autonomía, siendo simplemente Entes Preautonómicos.

Las competencias de las Comunidades Autónomas quedan pues definidas por remisión a la Constitución, a los Estatutos y, de forma residual, a lo que la Ley no declara como básico y competencia del Estado. As; pues, en el ámbito sanitario, las Comunidades Autónomas tienen asumidas competencias en las siguientes materias: 


\section{Sanidad e bigiene}

Funciones de desarrollo legislativo y ejecución —art. 148.1.21 CE—. Todas las Comunidades Autónomas recibieron, mediante los oportunos Reales Decretos de transferencias, las funciones y servicios necesarios para el ejercicio de estas competencias ya asumidas.

\section{Seguridad Social}

Funciones de desarrollo legislativo y ejecución de la legislación básica, salvo las normas que configuran el régimen económico de la misma. Se refiere a la asistencia sanitaria, una vez que esta se financia en su mayor parte por los Presupuestos Generales del Estado. Varias Comunidades Autónomas -Andalucía, Canarias, Catalunya, Comunidad Valenciana, Galicia, Navarra y País Vasco- han recibido el correspondiente traspaso de funciones y servicios que les permiten el ejercicio de esta competencia ya asumida.

\section{Productos farmacéuticos}

Función ejecutiva de la legislación del Estado. La Ley Orgánica 9/1992, de 23 de diciembre, delegó esta competencia en las Comunidades Autónomas llamadas de segundo grado, teniendo en cuenta que las otras ya la tenían por sus Estatutos.

\section{Ordenación farmacéutica}

Este conjunto de competencias sólo figuran como tales en los Estatutos de Autonomía de las Comunidades Autónomas denominadas de primer grado, pero el Tribunal Constitucional las ha entendido incluidas dentro de las de «sanidad e higiene», por lo que actualmente las ostentan todas las Comunidades Autónomas.

\subsection{EL INFORME ABRIL ${ }^{5}$}

En este apartado se pretende presentar un resumen genérico del Informe Abril, especialmente de las propuestas elaboradas por la Comisión de Análisis y Evaluación del Sistema Nacional de Salud, o Comisión Abril [1991].

5. Este epígrafe está basado en el Capítulo VII del libro escrito por Javier Elola «Sistema nacional de salud: evaluación de su eficiencia y alternativas de reforma. Barcelona. SG Editores S.A. [1994, pp. 125-137]», en el texto «Sucinta descripción del Sistema y evaluación del mismo. Apéndice al Informe de la Comisión. Comisión de Análisis y Evaluación del Sistema Nacional de Salud [1991, pp. 5-38]» y en el texto «Informe y Recomendaciones. Comisión de Análisis y Evaluación del Sistema Nacional de Salud [1991, pp. 5-64]». 
La Comisión de Análisis y Evaluación del Sistema Nacional de Salud realizó 64 recomendaciones, sobre las cuales se centró el debate, que abordan casi todos los aspectos más relevantes del sistema sanitario español; su análisis ordenado posibilita referirse a otras propuestas complementarias o alternativas. La Comisión Abril recabó la opinión de múltiples organizaciones sociales, sociedades científicas y expertos, recogiendo estas manifestaciones en 9 volúmenes cuyo contenido no ha sido, hasta el momento, estudiado sistemáticamente, siendo este uno de los trabajos pendientes que tiene el sistema para estudiar las alianzas y las resistencias a las reformas desde los posicionamientos de los distintos actores de la sanidad española.

\subsubsection{EL CONTEXTO HISTÓRICO Y POLÍTICO INFORME ABRIL}

El Grupo Parlamentario del Centro Democrático y Social _CDSpresentó, en enero de 1990, una Proposición no de Ley ante el Pleno del Congreso, por la que se instaba al Gobierno a «la constitución de una comisión para la revisión del Sistema Nacional de Salud y las tendencias de su entorno en el momento actual y de cara al futuro». En febrero del mismo año, el Pleno del Congreso aprobaba la mencionada propuesta, creando una comisión de expertos para el «Análisis, evaluación y propuesta de mejoras en el Sistema Nacional de Salud».

El Consejo Interterritorial del Sistema Nacional de Salud, cumpliendo el mandato parlamentario, constituyó, en junio de 1991, la mencionada Comisión, la cual, bajo la presidencia de Abril Martorell, quien había sido vicepresidente de Gobierno con la Unión de Centro Democrático, inició sus trabajos en septiembre del mismo año, concluyéndolos en julio de 1992.

La propuesta del CDS coincidía con una necesidad del Ministerio de Sanidad y Consumo y del PSOE para encontrar respuestas a unos problemas que no se habían planteado durante la elaboración de la Ley General de Sanidad.

En 1990, cuatro años después de aprobar la Ley General de Sanidad, y sin haberla puesto en práctica en aspectos importantes, era ya evidente la necesidad de ejercer un control más eficaz sobre el gasto sanitario, ante un menor crecimiento de la economía; así como que las reformas iniciadas no habían logrado la adhesión de los profesionales sanitarios — la huelga de los hospitales de 1987 fue la manifestación más extrema de este descontento_-, ni mejorado cualitativamente la imagen de la sanidad pública, ni aumentado la satisfacción de sus usuarios — con excepción de los centros de salud cuya cobertura no llegaba al 50\% de la población-, [Elola, 1994, p. 126]. 
La nueva situación se presentaba en una etapa de incertidumbre entre los responsables políticos de la sanidad. En diciembre de 1990, el Ministerio de Sanidad y Consumo había procedido a su enésima remodelación, suprimiendo la Secretaría General de Asistencia Sanitaria, órgano que, dirigido por Eduardo Arrojo, había defendido una línea de gestión empresarial de la sanidad pública [Arrojo, 1991], frente a las reticencias de la Seguridad Social. Por otro lado, el PSOE estaba sumido en una reflexión crítica —Documento de Teruel; El Médico, 6 de noviembre de 1987_, en la que los análisis de los problemas no se acompañaban de propuestas de reforma [Elola, 1991, pp. 33-68].

La creación de una comisión de expertos se inspiraba en experiencias similares en otros países — la Comisión cita al Reino Unido, Holanda y Suecia—, en las que expertos realizan, antes del debate político, el análisis de los problemas y sugieren las reformas necesarias.

La selección de los componentes y, por tanto, la orientación del análisis y las propuestas, están, a priori, condicionados por los gobiernos que hacen el encargo; en el caso de la Comisión Abril, la composición de sus miembros, alejada en general de la ideología del gobierno socialista, se justificó en la búsqueda del consenso en el seno del Consejo Interterritorial del Sistema Nacional de Salud.

La culminación de los trabajos de la Comisión Abril coincidió con un debate general sobre la privatización de los servicios públicos, en el que el discurso político, protagonizado por los agentes económicos y sociales, no atendía a matices sobre el concepto de privatización en sanidad.

A este contexto general, que no favoreció un debate eficaz sobre los análisis y propuestas de la Comisión, se sumó un notable error en la gestión política del informe, como fue su entrega, directa y escenografiada ante los medios de comunicación social, al Ministro de Sanidad y Consumo, en lugar de haber realizado la presentación a quien realizó el encargo: el poder legislativo [Elola, 1994, p. 127]. El mencionado error en la presentación del documento de la Comisión Abril se saldó confundiendo las opiniones y recomendaciones de la Comisión con la postura del gobierno, lo que provocó un rechazo inmediato de la mayoría de los agentes sociales.

Comisiones Obreras, la Confederación Estatal de Consumidores y Usuarios, la Confederación de Sindicatos Independientes de Funcionarios, el Sindicato de Auxiliares de Enfermería, el Sindicato de Ayudantes Técnicos Sanitarios, la Unión Demócrata de Jubilados y Pensionistas, la Unión General de Trabajadores, entre las organizaciones sociales; Izquierda Unida y el Partido Popular, entre los partidos políticos; y, dentro de la Administración, la Secretaría General de la Seguridad Social mostraron su rechazo global al mismo. 
El informe Abril se convirtió en un arma arrojadiza para la oposición, en lugar de contribuir a centrar el debate político sobre el análisis y las propuestas de unos expertos que, en general, no se caracterizaban por su identificación con la política sanitaria socialista.

\subsubsection{LA EVALUACIÓN DE LA COMISIÓN ABRIL SOBRE EL SISTEMA NACIONAL DE SALUD}

El resumen de la evaluación del sistema realizada por la Comisión de Análisis

y Evaluación del Sistema Nacional de Salud se recoge en los apartados 2 — evaluación del sistema—, y 3 — calidad, equidad y eficiencia del sistema-.

Los datos más destacados de esta evaluación son los siguientes:

- Crecimiento del gasto sanitario a ritmos superiores a la media de la OCDE, producido por un aumento del gasto público, en especial durante el quinquenio 1986-1991, debido a varios factores: entrada en vigor de la Ley General de Sanidad, menores restricciones presupuestarias, aumento del gasto público en farmacia, aumento del gasto hospitalario, incremento de los gastos de personal y descentralización del gasto en las Comunidades Autónomas.

- Sistema de financiación inadecuado, por la insuficiencia presupuestaria, multiplicidad de fuentes de financiación y financiación del gasto transferido en base a la evolución del gasto del Insalud gestionado por la administración central del Estado. A este análisis, que coincidía con el realizado por el Ministerio de Economía y Hacienda, la Comisión Abril añadió la «opacidad» que, para el ciudadano, suponía una financiación mayoritaria de la sanidad pública vía ingresos del Estado, en contraposición a la cuota sanitaria de la Seguridad Social, eliminada en 1979.

- La Comisión Abril recoge textualmente los inconvenientes que, para Arrojo - Anexo III del Informe-, tiene la falta de separación entre los servicios sanitarios y las Administraciones Públicas, en el sentido de la confusión de sus respectivos papeles, así como por atraer una administración burocrática a la gestión de los servicios. A esta crítica sobre el funcionamiento, la Comisión añadió la consideración de que «el inevitable exceso de regulación que el Sistema comporta impide el desarrollo de iniciativas, así como la renovación y mejora de la oferta asistencial privada». 
- Marco laboral estatutario inadecuado. La Comisión hace referencia a aspectos destacados en capítulos anteriores, como la incapacidad para aplicar incentivos, o la falta de autonomía de contratación y gestión por los centros; sin embargo, existe en el informe de la Comisión una notable ausencia de referencias sobre otros aspectos relevantes, como el carácter vitalicio de los puestos de Jefes de Servicio de los hospitales o la compatibilidad entre el ejercicio público y privado de la sanidad. Navarro [1991, pp. 7-18], entre otros [Ginestal, 1993, pp. 101-107], ha insistido en la importancia de este aspecto en un marco de gestión empresarial.

- Insuficiente evaluación tecnológica.

- Limitaciones del modelo de prestación farmacéutica, fundado en la no-discriminación de medicamentos, precio en función de la novedad y aportación de los asegurados activos. Este diagnóstico se centra en el resumen ejecutivo del informe de la Comisión, en la sobreprescripción de fármacos y el posible fraude en la utilización de recetas de pensionista. La aproximación de la Comisión Abril al problema del gasto farmacéutico es claramente insuficiente y no toma en consideración algunas medidas introducidas en otros sistemas sanitarios para el control del gasto. En la subcomisión de Farmacia de la Comisión Abril se produjo una quiebra práctica en los planteamientos de dos grupos de ponentes. El informe final y las recomendaciones de la Comisión recogieron las tesis más próximas a las corporaciones farmacéuticas, [Elola, 1994, p. 130].

- En relación con la atención sanitaria, primaria y hospitalaria, el informe de la Comisión Abril hace énfasis en la burocracia de la gestión, destacando «el excesivo consumo de medios diagnósticos y terapéuticos» por la atención primaria, que sobrecargaría a los hospitales, a través de unas urgencias y consultas externas masificadas. La Comisión destaca también las listas de espera en los hospitales. El análisis de la Comisión tampoco se mostró en sintonía con el informe de la subcomisión de Atención Primaria formada en su seno.

- Carga impropia sobre el sistema sanitario, por el déficit en servicios sociales.

- Sector privado «subordinado» al público, falta de incentivos para la homologación y acreditación de los centros sanitarios privados, y de ayudas para su modernización. 
- Mercado restringido para el sector asegurador privado, con una regulación administrativa obsoleta, que dificulta la libre economía entre profesionales y aseguradoras, así como entre estas y sus clientes.

- Buen nivel de asistencia técnica en los servicios hospitalarios, que contrasta con un servicio no orientado al usuario, por lo que las quejas son más de carácter burocrático—administrativo y de servicios colaterales, que propiamente asistenciales. Este análisis incide sobre una importante dimensión de la relación entre los ciudadanos y sistema sanitario, la de cliente, pero no atiende a los aspectos relativos a la participación ciudadana.

- Logro de una equidad básica, que es puesta en peligro por la ausencia de una definición explícita de las prestaciones y normas de acceso a los servicios, así como por los defectos del sistema de financiación.

- La estructura del sistema, así como el proceso de asignación y gestión presupuestaria de los recursos, no favorece la eficiencia en la gestión.

\subsubsection{PROPUESTAS DE REFORMA DE LA COMISIÓN ABRIL SOBRE EL SISTEMA NACIONAL DE SALUD}

El «Informe y Recomendaciones» de la Comisión de Análisis y Evaluación del Sistema Nacional de Salud se articulan sobre dos grupos de propuestas: Las bases para la reforma y un conjunto de 64 recomendaciones concretas.

La trascripción y el análisis de estas propuestas se centrará sobre las bases, refiriéndose sólo a las recomendaciones efectuadas por la Comisión Abril sobre los distintos aspectos abordados en la tesis.

\subsubsection{PROPUESTAS SOBRE LA ORGANIZACIÓN Y GESTIÓN}

La separación de las funciones de financiación, compra y provisión constituía, como en la reforma del Servicio Nacional de Salud británico [DHSS, 1989], la piedra angular de las reformas propuestas por la Comisión. Esta es una línea de reforma que se está desarrollando en sistemas sanitarios basados en el esquema de Servicio Nacional de Salud [OCDE, 1993].

La necesidad de diferenciar funciones dentro del Sistema Nacional de Salud es compartida, como se ha mencionado, por numerosos autores, y esta particular forma organizativa, entre otros, por Ibern [1992, pp. 77_86]. 
Las áreas de salud asumirían, dentro de la mencionada separación de funciones, la de compra de servicios, estableciendo un «mercado interno», en el que competirían proveedores públicos y privados. Para ello, las áreas de salud deberían tener una dimensión poblacional superior a la establecida por la Ley General de Sanidad —250.000 habitantes-.

Dentro de la competencia entre sector público y privado, la Comisión sugería evaluar las experiencias de gestión privada del aseguramiento público-MUFACE, empresas colaboradoras-, y aplicar las conclusiones -modificación, mantenimiento o impulso- que resultasen procedentes.

La Comisión recomendaba la transformación de los centros sanitarios en sociedades públicas —empresas de titularidad pública—. Esta propuesta es, asimismo, compartida por numerosos autores, entre ellos Navarro [1991, pp. 7-18].

En el marco de una gestión empresarial, la Comisión proponía que el personal estatutario mantuviera su régimen, con mayor autonomía de la dirección del centro sanitario en la aplicación de las facultades de recompensa y sanción, así como para negociar las partes variables de las retribuciones.

Para el personal de nuevo ingreso, recomendaba el régimen laboral. La vinculación del personal al sistema está condicionada por la naturaleza jurídica de este, y no cabría un régimen estatutario - funcionarial - dentro de una organización empresarial.

El mencionado esquema organizativo y de gestión empresarial era complementado por un amplio número de recomendaciones concretas sobre aspectos de gestión que, como la medición del producto, la facturación interna, o el desarrollo de los presupuestos clínicos, tienen un carácter instrumental.

Sin embargo, dentro de los aspectos de gestión, destacaba un nítido decantamiento hacia la contratación externa como vía principal para la incorporación de tecnología al sistema.

\subsubsection{PROPUESTAS SOBRE LA FINANCIACIÓN}

Las bases de la reforma propuesta por la Comisión Abril, en lo relativo al sistema de financiación se sustentaban sobre las siguientes premisas:

- El crecimiento del gasto sanitario durante la próxima década será inexorable, y los recursos públicos no podrán financiar la totalidad de este aumento, o mantener la participación del gasto sanitario público sobre el total. 
- La escasa participación de las cotizaciones sociales en la financiación de la sanidad dificulta la percepción por el usuario de que no es un bien a coste cero.

- Las desviaciones del presupuesto sanitario deberían financiarse con endeudamiento específico.

- La contribución del usuario en el coste de los servicios, en el momento de su uso, es una fuente adicional de ingresos, impulsa el desarrollo de sistemas de facturación y aumenta la conciencia sobre el coste de los servicios.

Estos criterios, cuyo soporte lógico o evidencia empírica no están suficientemente documentados en el informe de la subcomisión de Gestión y Financiación del sistema, coinciden básicamente con el razonamiento que sustentaba las propuestas privatizadoras, [Elola, 1994, p. 133].

En función de las referidas bases de la reforma, la Comisión Abril recomendó un conjunto de medidas, siendo estas las que, en mayor medida, sirvieron de argumento para la ya referida contestación social:

- Participación de los usuarios en el pago de los servicios. Las cantidades serían, «en principio», casi simbólicas.

- Definición de las prestaciones básicas, financiadas públicamente. La Comisión propuso que, en ausencia de otro criterio, estas prestaciones fueran las «que se estuviesen dispensando en todo el territorio nacional en el momento de la aprobación de la Ley General de Sanidad».

- Extensión de la contribución del usuario en la prestación farmacéutica a los pensionistas. El resto de los aspectos relativos al gasto farmacéutico se salda con una referencia a la mejor formación «farmacológica» de los médicos, así como a que «en adelante, debería disociarse el hecho técnico-administrativo de la inscripción de un nuevo medicamento en el registro farmacológico, de la inclusión automática en una lista de compras del sistema».

\subsubsection{RESUMEN DE LAS PROPUESTAS DE LA COMISIÓN ABRIL}

A falta de un estudio pormenorizado sobre las numerosas opiniones recabadas por la Comisión de Análisis y Evaluación del Sistema Nacional de salud, y obviando el hecho de que el informe — y la discusión posterior — se centra sobre los problemas de organización — sanidad—y no de salud — de la población—, o de «rendimiento social» del sistema [Spagnolo, 1993, pp. 258 - 263], existe un 
conjunto de aspectos enormemente llamativo que, junto a la inadecuada gestión política del informe, posiblemente contribuyeron a su fracaso, en el sentido de la escasa incidencia en el desarrollo practico de algunas de las propuestas sobre las que existía — y existe - un amplio consenso. Estos aspectos son los siguientes:

- Una discrepancia fundamental entre las bases de la reforma propuesta por la Comisión Abril y la ideología socialdemócrata que, al menos teóricamente, sustentaba las alianzas del gobierno socialista [Navarro, 1991, pp. 7-18]. La identificación conservadora del informe dificultó la defensa de algunas reformas, perfectamente compatibles con una aproximación progresista a los problemas de la sanidad española. Un ejemplo de ello es la mencionada contraposición entre eficiencia y equidad.

- Un nivel de elaboración técnica de las propuestas, inferior al que cabría esperar de la acreditada solvencia de los miembros de la Comisión, así como del enorme esfuerzo de asesoramiento y documentación realizado [López, 1991, pp. 99-105; Navarro, 1991, pp. 7-18]. Entre estas recomendaciones poco fundamentadas destaca la de retrotraer la cobertura de prestaciones básicas a las existentes en 1986, o el empeño de la Comisión Abril en hacer más perceptible para los ciudadanos la financiación de la sanidad, mediante cotizaciones de la Seguridad Social [López, 1991, 99-105].

- El informe final no recoge opiniones diferenciadas que se habían dado en el seno de algunas subcomisiones y de una parte de los miembros de la de Farmacia. Este hecho, junto a la escasa consistencia de algunas propuestas, contribuyó a dar una sensación de recomendaciones escritas «a priori» y, por tanto, a una mayor identificación con la postura gubernamental.

- La ausencia de referencias sobre algunos problemas que habían sido centros de debate en la sanidad pública española durante los años 80 [Elola, 1991, pp. 33-68]; entre ellos, la compatibilidad de ejercicio profesional, la figura de los Jefes de Servicio hospitalarios, los conciertos entre el Insalud y corporación farmacéutica, o los relativos a la participación ciudadana.

El informe de la Comisión Abril se saldó con un fracaso, tanto en la gestión política del debate como en la incapacidad para llevar a la practica las propuestas de reforma más relevantes [Elola, 1994, p. 135]. Las razones de este tropiezo estarían, de conformidad con el análisis realizado, producidas por el contexto 
político general, así como por las insuficiencias y contradicciones del propio informe; una explicación alternativa, apuntada por Ortún y López [1993, pp. 15-31], sería la escasa posibilidad que tiene el plantear una reforma «global», en lugar de desarrollar reformas más selectivas.

Según Elola [1994, pp. 135-137], las recomendaciones de la Comisión Abril, se pueden agrupar en tres grandes grupos:

1. Aquellas sobre las que existe la posibilidad de alcanzar un consenso suficiente, en especial si se supera el falso debate entre eficiencia y equidad. Entre ellas, se pueden señalar:

1.1. La definición de un conjunto básico de prestaciones cubiertas por el Sistema Nacional de Salud.

1.2. Laseparacióndefunciones de financiación,compra-aseguramientoy provisión. Este objetivo inspira la reforma, realizada en 1992, de la estructura del Ministerio de Sanidad y Consumo, así como la ordenación del Servicio Catalán de Salud, de 1990, y la propuesta de reforma del Servicio Vasco de Salud, aprobada por su Parlamento en 1993. Esta separación de funciones incluye, a través del Real Decreto de 1992 sobre financiación selectiva de medicamentos, la recomendación del informe de la Comisión Abril de separar el registro de fármacos de la decisión sobre su financiación por el Sistema Nacional de Salud; si bien las competencias sobre ambas funciones siguen estando depositadas en el mismo órgano de la Administración.

1.3. El desarrollo de una gestión empresarial en la sanidad pública, con una vinculación del personal más acorde que la actual con este funcionamiento. Algunas iniciativas de los Servicios de Salud de las Comunidades Autónomas parecen decantarse en este sentido.

2. Las recomendaciones de la Comisión Abril, que no tienen una base teórica o empírica contrastada, o no cuentan con un consenso suficiente, u obedecen a un posicionamiento ideológico de carácter conservador. Entre ellas, destacan aquellas que provocaron más polémica:

2.1. Contribución del usuario, incluyendo la de los pensionistas, en la prestación farmacéutica.

2.2. Recorte de prestaciones, reduciéndolas a las existentes en 1986.

2.3. Privatización de los servicios, a través del desarrollo de un «mercado interno», dando entrada a servicios privados que competirían libremente con los públicos para captar los recursos destinados a la 
compra de servicios en cada área; en contraposición al modelo, también analizado por los expertos de la Comisión Abril, de competencia pública, en el que se produce una competencia entre servicios autorizados en la oferta pública para captar a los pacientes de cada área.

2.4. Desarrollo tecnológico del sistema basado en la contratación externa de servicios, descansando sobre la iniciativa privada este factor estratégico de crecimiento del gasto.

3. Por último, los aspectos de la reforma, que siendo relevantes dentro del análisis realizado, no son afrontados por la Comisión Abril: incompatibilidades, puestos vitalicios de Jefes de Servicio de hospitales, conciertos con las corporaciones de farmacia, y participación ciudadana, incluyendo, dentro de esta última, el papel de los ayuntamientos en la gestión de la sanidad.

\subsection{CONCLUSIONES DEL CAPÍTULO}

En los países desarrollados existen dos modelos básicos de organización de la asistencia sanitaria pública: el mutualista y el impositivo. El primero responde a una organización basada en la Seguridad Social, con financiación basándose en cuotas sobre el trabajo, y tiene su origen en el diseño elaborado hace más de cien años por Bismarck en Alemania. El segundo basa su financiación en los impuestos y fue introducido en Inglaterra por Lord Beveridge tras la Segunda Guerra Mundial.

En el modelo mutualista -Alemania, Bélgica, Francia, Holanda y Luxemburgo-, la provisión de servicios acostumbra a ser indirecta, es decir, hay una clara diferenciación entre la entidad financiadora — Seguridad Social—y las entidades proveedoras. En general, los médicos trabajan en sus consultas particulares y los hospitales no tienen una finalidad lucrativa; la presencia de la Iglesia es importante, aunque también los hay totalmente privados.

En el modelo impositivo —Dinamarca, España, Grecia, Inglaterra, Irlanda, Italia y Portugal-, la provisión de servicios acostumbra a ser mixta, es decir, coexisten servicios de propiedad de la entidad financiadora -Administración pública- con otros servicios contratados. En general, los hospitales son públicos, y en algunos casos se contrata a otros centros de finalidad no lucrativa. La atención primaria es también pública en algunos países —España, Grecia y Portugal—, mientras que en otros también se lleva a cabo mediante contrato. Pese al importante peso de la oferta y la cobertura pública, en casi todos los países existe oferta privada, tanto de atención 
primaria como hospitalaria.

En general, los países de modelo impositivo tienen un gasto sanitario, público y total, expresado en porcentaje sobre el PIB, inferior al de los países de modelo mutualista. Igualmente, las diferentes políticas de contención de costes, orientadas a la demanda en los mutualistas y a la oferta en los impositivos, puestas en marcha como consecuencia de la crisis de los setenta, han evidenciado la existencia de un mayor control en los países con modelos impositivos.

En este contexto general, el modelo español presenta una serie de peculiaridades que conviene destacar. El modelo español nace como una adaptación tardía del modelo mutualista. De hecho, en un principio, a comienzos de siglo, tan sólo cubría la accidentalidad laboral; posteriormente, a comienzos de los años cuarenta, cubre la enfermedad común en los trabajadores no cualificados del sector industrial —Seguro Obligatorio de Enfermedad-. A partir de ese momento se produce una extensión progresiva, no planificada y fragmentada, tanto al resto de los trabajadores industriales como a otros sectores, mediante la creación de regímenes especiales o con la inclusión de mutuas de previsión social ya existentes. Es en 1963, con la Ley de Bases de la Seguridad Social, cuando se concreta un primer intento globalizador.

Las importantes lagunas en la cobertura que existen durante todo este período fueron cubiertas por la beneficencia —atención gratuita para pobres-, de carácter religioso y municipal, y por el pago directo de la prestación de servicios, que ya existía. Estos servicios «de pago» fueron organizándose básicamente alrededor de los médicos, y dieron lugar a la aparición de los primeros «igualatorios», auténticos embriones de las compañías de seguros de asistencia médica. La evolución de la tecnología médica provocó un cierto proceso de concentración y la aparición de clínicas privadas, en general en torno a algún médico de particular prestigio.

Pese a que el modelo español se construyó sobre la base del modelo alemán, curiosamente se optó por una gestión directa de la provisión de servicios. El cambio de modelo de financiación, del mutualista al impositivo, producido en los últimos años, no viene acompañado de cambios sustanciales en el modelo organizativo y asistencial.

\subsubsection{ESCENARIOS DE EVOLUCIÓN POSIBLES}

El modelo actual, de base impositiva y organización autonómica, responde a las previsiones recogidas en la Ley General de Sanidad —1986—. Si bien el 
sector sanitario ha quedado fuera de los planes de convergencia europea suscritos en Maastricht, éstos prefiguran un macroescenario que indudablemente limita el margen de maniobra del sector. En este contexto, partiendo de un nivel de financiación pública del gasto sanitario similar en todos los países de la Unión Europea y de una preocupación compartida por la tendencia al crecimiento del gasto sanitario por encima del PIB, los elementos más relevantes para definir el posible escenario de futuro son los siguientes:

- Introducción y refuerzo de componentes impositivos en los sistemas.

- Aplicación de elementos de contención de costes sobre la oferta y demanda. Disciplina presupuestaria, tique moderador y mercados internos.

- Fortalecimiento de los criterios de prevención y promoción de la salud de eficacia probada en el marco de políticas de calidad de vida.

Así pues, creemos que el modelo sanitario español, si bien se mantendrá en lo fundamental, sufrirá modificaciones sustanciales derivadas de la introducción de dichos elementos. Respecto a la demanda de servicios, parece previsible un incremento importante en los servicios asistenciales paralelo al envejecimiento de la población y a otros factores de orden sanitario y sociológico. En el caso de los servicios de salud pública, se relacionará con el mayor interés por la salud y por las políticas de calidad de vida. En ambos grupos de servicios, el incremento de renta per cápita provocará previsiblemente un aumento de su demanda. Finalmente, parece previsible también que el incremento del gasto sanitario por encima del PIB se producirá básicamente a expensas del sector privado. 